\title{
KEHILANGAN NITROGEN PADA SISTEM USAHATANI JAGUNG MANIS DI LAHAN GAMBUT KALIMANTAN TENGAH (Nitrogen Lost on Sweet Corn Of Peatland Farming System in Central Kalimantan)
}

\author{
Suparto, H. ${ }^{1)}$ \\ ${ }^{1)}$ Jurusan Budidaya Pertanian, Fakultas Pertanian UPR \\ Telpon : 085350158811 Email : hairusuparto@yahoo.co.id
}

Diterima : 22/02/2018

Disetujui : 07/05/2018

\begin{abstract}
Application of fertilizer can increase nitrogen loss in agricultural land in the form of leaching and volatilization. Research carried out on peat soil, done two times planting. First in the dry season to transition with nitrogen input from urea fertilizer, cow dung manure and from rainfall. Both are implemented in the month of transition to the rainy season with nutrient input from nitrogen derived from pearl NPK fertilizer, chicken manure and rainfall. Nitrogen washing is obtained from percolation water which is accommodated by lysimeter. The volume of percolation water measured at plant age 15, 30, $45 \mathrm{HST}$ and at harvest, $\mathrm{N}$ content in laboratory analysis. The purpose of this research is to know total nitrogen loss and efficiency level of sweet corn farming system in peatland. Nitrogen washing in the first study was $2.28 \mathrm{~kg} \mathrm{~N}$ ha- 1 or $2.49 \%$ and in the second study was $8.95 \mathrm{~kg} \mathrm{~N}$ ha- 1 or $13.65 \%$. The other estimated loss of volatilization in the first study was 12.80 $\mathrm{Kg} \mathrm{N}$ ha- 1 or $13.97 \%$ and in the second study it was $6.76 \mathrm{Kg} \mathrm{N}$ ha-1 or $10.31 \%$. Average loss estimated volatilization of $9.78 \mathrm{~kg} \mathrm{~N}$ ha-1 or $12.45 \%$ Total nitrogen loss of $19.60 \%$, so that sweet corn farming system on peatlands in Kalampangan Urban Palangkaraya is classified as inefficient
\end{abstract}

\section{Keywords: Nitrogen, Sweet Corn, Peat Land}

\begin{abstract}
ABSTRAK
Aplikasi pemberian pupuk dapat meningkatkan kehilangan nitrogen pada lahan pertanian berupa pencucian (leaching) dan penguapan (volatilisasi). Penelitian dilaksanakan pada tanah gambut ombrogen, dilakukan dua kali tanam. Pertama pada musim kemarau ke pancaroba dengan input hara nitrogen berasal dari pupuk urea, pupuk kotoran sapi dan dari curah hujan,.Kedua dilaksanakan pada bulan peralihan ke musim hujan dengan input hara nitrogen berasal dari pupuk NPK mutiara, pupuk kotoran ayam dan curah hujan. Pencucian nitrogen diperoleh dari air perkolasi yang ditampung dengan lysimeter. Volume air perkolasi di ukur pada umur tanaman 15, 30, 45 HST dan saat panen, kandungan $\mathrm{N}$ di analisis di laboratorium. Tujuan penelitian ini untuk mengatahui total kehilangan nitrogen dan tingkat efisiensi sistem usahatani jagung manis di lahan gambut. Pencucian nitrogen yang terjadi pada penelitian pertama sebesar $2.28 \mathrm{~kg} \mathrm{~N}^{-1}$ atau $2.49 \%$ dan pada penelitian kedua sebesar $8.95 \mathrm{~kg} \mathrm{~N}^{-1}$ atau $13.65 \%$. Kehilangan lainnya yang diperkirakan penguapan (volatilisasi) pada penelitian pertama sebesar $12.80 \mathrm{Kg} \mathrm{N}^{-1}$ atau $13.97 \%$ dan pada penelitian kedua sebesar $6.76 \mathrm{Kg} \mathrm{N}^{-1}$ atau $10.31 \%$. Rata-rata kehilangan yang diperkirakan penguapan (volatilisasi) sebesar $9.78 \mathrm{~kg} \mathrm{~N}^{-1}$ atau $12.45 \%$ Total kehilangan nitrogen sebesar $19.60 \%$, sehingga sistem usahatani jagung manis pada lahan gambut di Kelurahan Kalampangan Kota Palangka Raya tergolong tidak efisien.
\end{abstract}

Kata Kunci : Nitrogen, Jagung Manis, Lahan Gambut 


\section{PENDAHULUAN}

Tanah gambut memiliki porositas yang besar. berkisar antara 70 dan 95\% (Radjagukguk, 1993), sehingga bila terjadi hujan, tidak mampu menahan air dan terjadi air perkolasi ke bawah permukaan tanah, akibatnya terjadi pencucian (leaching), Sebaliknya bila musim kemarau tanah gambut cepat kering, akibatnya hara nitrogen mudah hilang karena menguap (volatilisasi). terutama hara nitrogen yang memiliki sifat mudah larut.

Nitrogen merupakan hara esiensial yang sangat diperlukan untuk pertumbuhan dan perkembangan tanaman. Kandungan $\mathrm{N}$ pada tanah gambut rendah yang disebabkan oleh $\mathrm{C} / \mathrm{N}$ rasio tinggi, dekomposisi lambat, proses nitrifikasi rendah, sehingga $\mathrm{N}$ bebas juga rendah (Hayden, et al., 2005 ; Kaye dan Hart, 1997 : Moore, 2008). dan tanaman jagung (Zeamays) memerlukan $50-80 \% \mathrm{~N}$ dari tanah (Salmeron, et al., 2007).

Untuk mengatasi masalah porositas dan rendahnya nitrogen para petani memberikan input berupa pupuk anorganik. Juga memberikan pupuk kompos selain kotoran sapi dengan tujuan selain menambah hara juga meningkatkan kemampuan menahan air.

Hara nitrogen yang berasal dari pupuk diserap tanaman dalam bentuk $\mathrm{NH}_{4}{ }^{+}$, atau $\mathrm{NO}_{3}^{-}$, namun tidak semua dapat diserap tanaman, sebagian tersisa dalam tanah dan sebagian lagi hilang. Kehilangan nitrogen dapat terjadi melalui dua proses yaitu pertama pencucian (leaching), dimana penempatan pupuk $\mathrm{N}$ yang kurang tepat di permukaan tanah atau di dalam tanah, akan larut terbawa aliran air perkolasi yang masuk melalui poripori tanah. Kedua disebabkan oleh volatilisasi ialah penguapan melalui sistem kapiler tanah dimana $\mathrm{NH}_{4}^{+}$yang terlarut dalam air bergerak ke lapisan atas dan hilang melalui proses evaporasi.

Kegiatan usahatani secara intensif dengan menggunakan banyak pemupukan akan memerlukan biaya yang cukup besar dan dikhawatirkan dapat mencemari lingkungan.
Selain itu berpotensi cukup tinggi terjadinya pencucian nitrogen (leaching) dan penguapan (volatilisasi) (Hoffman, et al. , 1999 ; Knudsen, et al., 2006 ; Torstensson, et al., 2006 ; Zhao, et al., 2010). Dengan demikian sistem usahatani di lahan gambut dianggap tidak efisien.

\section{BAHAN DAN METODE}

Penelitian dilakukan pada tanah gambut ombrogen di Kelurahan Kalampangan Kota Palangka Raya padabulan Agustus 2014 sampai Februari 2015. Analisis hara dilakukan di Laboratorium Jurusan Tanah Fakultas Pertanian Universitas Brawijaya dan laboratorium analitik Universitas Palangka Raya.

Penelitian ini dilakukan dua kali, pertama jagung manis ditanam dengan luas 14 $\mathrm{m}$ x $70 \mathrm{~m}$. Menggunakan varietas Bonanza ditanamdengan jarak tanam $40 \mathrm{~cm} \times 70 \mathrm{~cm}$, sebagai sumber $\mathrm{N}$ diberikan pupuk urea dengan takaran $150 \mathrm{~kg} \mathrm{ha}^{-1}$ dengan tiga kali pemberian yaitu pada tanamn umur 10, 20 dan 30 hari, sedangkan pupuk kompos kotoran sapi dengan takaran 2 ton ha ${ }^{-1}$ diberikan pada saat tanam. Pada penelitian kedua jagung manis ditanam dengan luas tanam $20 \mathrm{~m} \times 50$ $\mathrm{m}$. Menggunakan varietas Bonanza ditanam dengan jarak tanam $40 \mathrm{~cm}$ x $70 \mathrm{~cm}$, sebagai sumber hara diberikan pupuk NPK Mutiara dengan takaran $250 \mathrm{~kg}$ ha'1 yang diberikan 3 kali yaitu padatanaman berumur 10, 20 dan 30 hari, sedangkan pupuk kandang kotoran ayamdengan takaran2.2 ton $\mathrm{ha}^{-1}$ diberikan pada saat tanam.

Pencucian nitrogen diteliti dengan lysimeter (Barton, et al,.2005 ; Hepperly, et al,. 2009 ; Zhao, et al,. 2010). Lysimeter yang digunakan milik Centre For International CoOperation Management of Tropical Peatland (CIMTROP) terbuat dari plat baja dengan ukuran lebar $20 \mathrm{~cm}$ panjang $30 \mathrm{~cm}$, diletakkan di bawah akar tanaman dengan kedalaman 15 $\mathrm{cm}$ di bawah permukaan tanah, dengankemiringan $15^{0}$. Alat ini dihubungkan ke jerigen penampung air perkolasi dengan 
selang plastik. Data air perkolasi diukur pada saat tanaman berumur 15, 30, 45 hari dan saat panen, dihitung dengan rumus :

\section{$\mathbf{V}=[\mathbf{A H} / \mathbf{A L}] \times \mathbf{V T}$}

Dimana : $\mathrm{V}=$ Volume air perkolasi, $\mathrm{AH}=$ luas lahan, $\mathrm{AL}=$ luas lysimeter dan $\mathrm{VT}=$ volume air perkolasi dlm lysimeter per waktu pengukuran.

Kandungan nitrogen dalam air perkulasi dianalisis di Laboratorium, $\mathrm{NH}_{3}{ }^{+}$dengan metode titrasi, sedangkan $\mathrm{NO}_{3}{ }^{-}$ dan $\mathrm{NO}_{2}^{-2}$ dengan metode spektometri. Kehilangan lain yang diperkirakan pengauapan (volatilisasi) diperoleh dengan menghitung selisih input - output pada sistem usahatani jagung manis di lahan gambut.

\section{HASIL DAN PEMBAHASAN}

\section{Pemupukan}

Kegiatan pertanian secara intensif dengan menggunakan banyak pemupukan berpotensi cukup tinggi terjadinya pencucian hara N (Hoffman, et al. , 1999 ; Knudsen, et al., 2006 ; Torstensson, et al., 2006 ; Zhao, et al., 2010). Aplikasi pemberian pupuk dapat meningkatkan kehilangan $\mathrm{N}$ pada sistem tanah - tanaman, berupa pencucian dan penguapan (Alvarez, , et al., 2004). Total eksternal input hara nitrogen pada penelitian berasal dari pemberian pupuk yang secara rinci dapat dilihat pada Tabel 1 berikut.

Tabel 1. Total kandungan nitrogen dari pemupukan

\begin{tabular}{|c|c|c|c|c|}
\hline \multirow[b]{2}{*}{ No } & \multicolumn{2}{|c|}{ Penelitian I } & \multicolumn{2}{|c|}{ Penelitian II } \\
\hline & $\begin{array}{l}\text { Sumber } \\
\text { Nitrogen }\end{array}$ & $\begin{array}{c}\text { Kandungan N } \\
\left(\mathrm{kg} \mathrm{N} / \mathrm{ha}^{-1}\right)\end{array}$ & $\begin{array}{l}\text { Sumber } \\
\text { Nitrogen }\end{array}$ & $\begin{array}{c}\text { Kandungan N } \\
\left(\mathrm{kg} \mathrm{N} / \mathrm{ha}^{-1}\right)\end{array}$ \\
\hline 1 & Pupuk Urea & 69.0 & Pupuk NPK & 40.00 \\
\hline 2 & Pukuk Kotoran sapi & 22.2 & Pukuk Kotoran ayam & 25.08 \\
\hline 3 & Curah hujan & 0.40 & Curah hujan & 0.47 \\
\hline & Total & 91.6 & Total & 65.55 \\
\hline
\end{tabular}

Tabel 2 Data curah hujan dan volume air perkolasi pada penelitian I

\begin{tabular}{cccccc}
\hline \multirow{2}{*}{ No } & \multicolumn{2}{c}{ Tanggal } & \multicolumn{2}{c}{ Curah hujan } & \multicolumn{2}{c}{ Kandungan N Total } \\
& Terjadinya hujan & Vol $(\mathrm{ml})$ & Vol $(\mathrm{mm})$ & Hasil lab (mg/l) & $\mathrm{kg} \mathrm{N} \mathrm{ha}^{-1}$ \\
\hline 1 & 13 Oktober 2014 & 86 & 7.60 & 0.26 & 0.020 \\
2 & 27 Oktober 2014 & 185 & 16.37 & 0.16 & 0.026 \\
3 & 29 Oktober 2014 & 1154 & 102.09 & 0.02 & 0.020 \\
4 & 30 Oktober 2014 & 172 & 15.22 & 0.35 & 0.050 \\
5 & 4 Nopember 2014 & 975 & 86.25 & 0.30 & 0.259 \\
6 & 8 Nopember 2014 & 914 & 80.86 & 0.01 & 0.008 \\
7 & 12 Nopember 2014 & 1215 & 107.48 & 0.01 & 0.011 \\
8 & 16 Nopember 2014 & 605 & 53.52 & 0.01 & 0.005 \\
& Total & & & & 0.400 \\
\hline
\end{tabular}


Tabel 3.Pencucian nitrogen melalui air perkolasi pada penelitian I

\begin{tabular}{lccc}
\hline $\begin{array}{c}\text { Umur } \\
\text { Tanaman }\end{array}$ & $\begin{array}{c}\text { Volume Air Perkolasi } \\
(\mathrm{ml})\end{array}$ & $\begin{array}{c}\text { Kandungan N Total } \\
(\mathrm{mg} / \mathrm{l})\end{array}$ & $\begin{array}{c}\text { Kandungan N Total } \\
(\mathrm{kg} \mathrm{N} \text { ha-1) }\end{array}$ \\
\hline 15 hari & 845 & 7.68 & 1.11 \\
30 hari & 342 & 3.66 & 0.21 \\
45 hari & 6890 & 0.51 & 0.59 \\
Panen & 6900 & 0.32 & 0.37 \\
Total & $\mathbf{1 4 . 9 7 7}$ & $\mathbf{1 2 . 1 7}$ & $\mathbf{2 . 2 8}$ \\
\hline
\end{tabular}

Tabel 4. Data curah hujan dan volume air perkolasi pada penelitian II

\begin{tabular}{clcccc}
\hline \multirow{2}{*}{ No } & Tanggal & Curah hujan & \multicolumn{3}{c}{ Kandungan N Total } \\
& Terjadinya hujan & Vol $(\mathrm{ml})$ & Vol $(\mathrm{mm})$ & Hasil lab $(\mathrm{mg} / \mathrm{l})$ & $\mathrm{kg} \mathrm{N} \mathrm{ha}^{-1}$ \\
\hline 1 & 13 Oktober 2014 & 86 & 7.60 & 0.26 & 0.020 \\
2 & 27 Oktober 2014 & 185 & 16.37 & 0.16 & 0.026 \\
3 & 29 Oktober 2014 & 1154 & 102.09 & 0.02 & 0.020 \\
4 & 30 Oktober 2014 & 172 & 15.22 & 0.35 & 0.050 \\
5 & 4 Nopember 2014 & 975 & 86.25 & 0.30 & 0.259 \\
6 & 8 Nopember 2014 & 914 & 80.86 & 0.01 & 0.008 \\
7 & 12 Nopember 2014 & 1215 & 107.48 & 0.01 & 0.011 \\
8 & 16 Nopember 2014 & 605 & 53.52 & 0.01 & 0.005 \\
9 & 26 Nopember 2014 & 1150 & 101.73 & 0.01 & 0.010 \\
10 & 2 Desember 2014 & 1870 & 165.43 & 0.03 & 0.050 \\
11 & 12 Desember 2014 & 1340 & 118.54 & 0.01 & 0.012 \\
& Jumlah & & & & 0.471 \\
\hline
\end{tabular}

Tabel 5. Pencucian nitrogen melalui air perkolasi pada penelitian II

\begin{tabular}{cccc}
\hline $\begin{array}{c}\text { Umur } \\
\text { Tanaman }\end{array}$ & $\begin{array}{c}\text { Volume Air Perkolasi } \\
(\mathrm{ml})\end{array}$ & $\begin{array}{c}\text { Kandungan N Total } \\
(\mathrm{mg} / \mathrm{l})\end{array}$ & $\begin{array}{c}\text { Kandungan N Total } \\
\left(\mathrm{kg} \mathrm{N} \mathrm{ha}^{-1}\right)\end{array}$ \\
\hline 15 hari & 48 & 3.96 & 0.032 \\
30 hari & 10835 & 2 & 3.612 \\
45 hari & 5350 & 1.48 & 1.319 \\
Panen & 8860 & 2.7 & 3.987 \\
Total & $\mathbf{2 5 . 0 9 3}$ & $\mathbf{1 0 . 1 4}$ & $\mathbf{8 . 9 5}$ \\
\hline
\end{tabular}

\section{Curah Hujan}

Eksternal input hara nitrogen dapat berasal dari curah hujan (Grimshaw, et al., 2002; Raubuch, et al., 1998; Ahmad-Shah et al., 1992). Volume (dalam satuan $\mathrm{ml}$ ) curah hujan dicatat dengan menggunakan alat sederhana berupa corong yang dihubungkan dengan penampung, Cuplikan air hujan yang diambil pada setiap hari terjadinya hujan. Data diubah ke dalam satuan $\mathrm{mm}$ dengan persamaan:

$$
\text { Ch }=[\text { Vah } / \text { Amp }] \text { x } 10
$$


di mana : $\quad$ Ch $=$ curah hujan $(\mathrm{mm}) ;$ Vah $=$ volume 1 liter air hujan (cm3); Amp = luas mulut penakar $(\mathrm{cm} 2)$.

Jatuhan hujan secara langsung bukan hanya menjadi input hara nitrogen bagi lahan usahatani di lahan gambut, tetapi karena lahan gambut memiliki porositas yang besar, maka dengan semakin besar curah hujan yang terjadi, semakin besar pula terjadinya air perkolasi yang memungkinkan semakin besar pula terjadinya pencucian nitrogen.

\section{Kehilangan Nitrogen}

Kehilangan nitrogen pada sistem usahatani dapat terjadi melalui dua proses yaitu pencucian (leaching) dan penguapan (volatilisasi). Kehilangan $\mathrm{N}$ dari pemupukan rata-rata berkisar antara $0-17 \%$.(Sun, et al., 2004). Pada penelitian pertama terjadinya kehilangan $\mathrm{N}$ akibat pencucian sebesar 2.28 $\mathrm{kg} \mathrm{N} \mathrm{ha}^{-1}$ atau $2.49 \%$ (Tabel 3). Terjadi secara fluktuatif, hal ini disebabkan pemupukan anorganik yang dilakukan oleh petani diberikan secara bertahap dan dengan semakin bertambahnya umur tanaman semakin banyak pula hara nitrogen yang mampu diserap oleh tanaman.

Kehilangan nitrogen pada penelitian kedua sebesar $8.95 \mathrm{~kg} \mathrm{~N}$ ha $^{-1}$ atau $13.65 \%$ (Tabel 5). Terjadinya peningkatan pencucian nitrogen disebabkan tingginya intensitas curah hujan pada umur tanaman di atas 15 hari, sehingga dengan semakin besar intensitas curah hujan, semakin besar terjadinya air perkolasi, akibatnya semakin besar pula terjadinya pencucian nitrogen.

Rata-rata terjadinya pencucian nitrogen dari kedua penelitian secara rinci dapat dilihat pada Tabel 6 .

Rata-rata pencucian nitrogen dari kedua penelitian sebesar $5.62 \mathrm{~kg} \mathrm{~N} \mathrm{ha}^{-1}$ atau $7.15 \%$.. Hal ini dikarenakan kebiasaan petani di Kelurahan Kalampangan memberikan pupuk majemuk NPK Mutiata yang berbentuk butiran (granular) dilarutkan dulu dalam air, kemudian disiramkan dengan lobang tanam, sehingga bila terjadi hujan pupuk mudah larut.

Tabel 6. Kecendrungan terjadinya pencucian nitrogen pada saat penelitian

\begin{tabular}{|c|c|c|c|c|}
\hline \multirow{2}{*}{ Peneltian } & \multicolumn{4}{|c|}{ Kandungan $\mathrm{N}$ Total $\left(\mathrm{Kg} \mathrm{ha}^{-1}\right)$ pd umur tanaman } \\
\hline & 15 hari & 30 hari & 45 hari & Panen \\
\hline Pertama & 1.11 & 1.32 & 1.91 & 2.28 \\
\hline Kedua & 0.03 & 3.64 & 4.96 & 8.95 \\
\hline Rata-rata & 0.57 & 2.45 & 3.40 & 5.62 \\
\hline
\end{tabular}

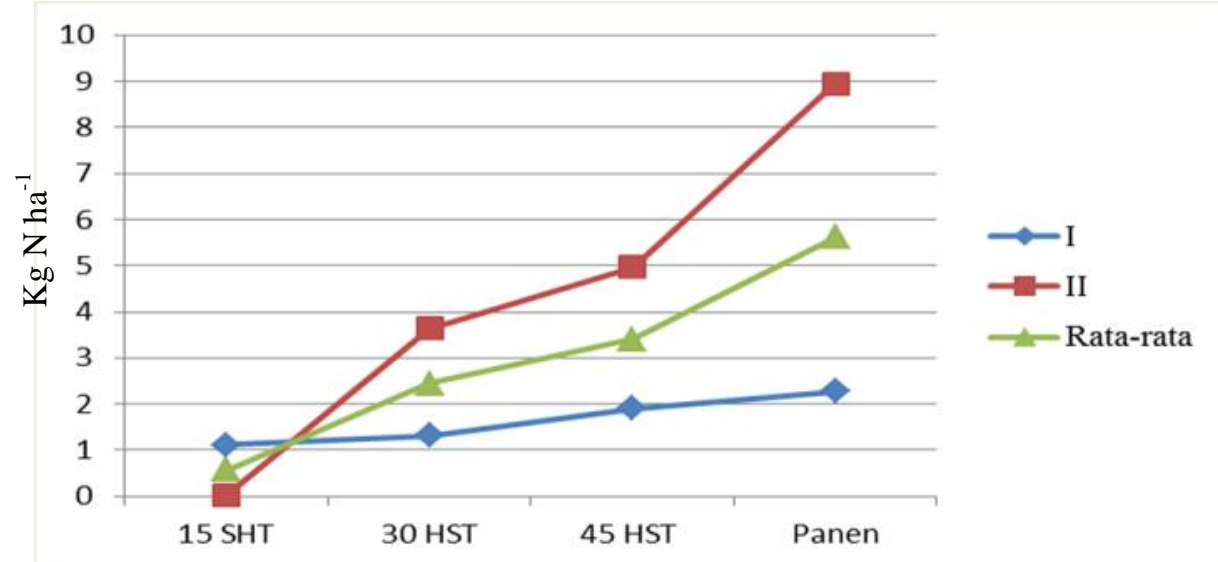

Gambar 1. Grafik terjadinya pencucian nitrogen 
Tabel 6. Input-output nitrogen pada sistem usahatani jagung manis

\begin{tabular}{llccc}
\hline \multirow{2}{*}{ No } & \multicolumn{1}{c}{ Sumber Bahan } & \multicolumn{2}{c}{ Kandungan N Total (Kg N ha-1) } & \multirow{2}{*}{ Rata-rata } \\
& & Penelitian I & Penelitian II & \\
\hline & Input & 69.00 & 40.00 & 54.5 \\
1 & Pupuk Anorganik & 22.20 & 25.08 & 23.64 \\
2 & Pupuk Organik & 0.4 & 0.47 & 0.44 \\
3 & curah hujan & 91.60 & 65.55 & 78.58 \\
& Total & & & \\
& Output & 0.08 & 1.48 & 0.78 \\
1 & Selisih analisis awal dan akhir tanah & 29.09 & 20.68 & 24.89 \\
2 & Panen (tongkol berkelobot) & 47.35 & 27.68 & 37.51 \\
2 & Sisa panen (batang, daun dan akar) & 2.28 & 8.95 & 5.62 \\
3 & Pencucian nitrogen & 12.80 & 6.76 & 9.78 \\
4 & Kehilangan lainnya & 91.6 & 65.55 & 78.58 \\
& Total & 0 & 0 & 0
\end{tabular}

Dari Gambar 3 di atas ternyata semakin bertambahnya umur tanaman, semakin meningkatkan pula terjadinya pencucian nitrogen. Rata-rata pencucican nitrogen pada kedua penelitian sebesar 5.62 $\mathrm{kg} \mathrm{N} \mathrm{ha}{ }^{-1}$ atau $7.15 \%$.

Kehilangan nitrogen lainnya yang diprediksi penguapan (volatilisasi) diperoleh dengan menghitung selisih input - output pada kedua penelitian yang secara rinci dapat di lihat pada Tabel 6 .

Dari Tabel 6 kehilangan nitrogen lainnya yang diprediksi penguapan (volatilisasi) pada penelitian pertama sebesar $12.80 \mathrm{Kg} \mathrm{N}^{-1}$ atau $13.97 \%$ dan pada lokasi kedua sebesar $6.76 \mathrm{Kg} \mathrm{N}^{-1}$ atau $10.31 \%$ dengan rata-rata kehilangan sebesar $9.78 \mathrm{~kg} \mathrm{~N}$ ha $^{-1}$ atau $12.45 \%$. Total kehilangan nitrogen yang berasal dari pencucian (leaching) dan penguapan (volatilisasi) sebesar $19.60 \%$.

\section{Pembahasan}

Bahan organik yang berasal dari pupuk (organik dan an organik) yang diberikan pada lahan gambut mengalami proses amonifikasi ialah menghidrolisis senyawa N-organik dengan melepaskan $\mathrm{NH}_{3}$ atau $\mathrm{NH}_{4}{ }^{+}$(Jansson, et al., 1982; Hayes, 1986; Otabbong, et al.,1993). Kemudian pada kondisi aerob mengalami proses nitrifikasi ialah proses oksidasi enzimatik amonium $\left(\mathrm{NH}_{4}^{+}\right)$menjadi nitrit $\left(\mathrm{NO}_{2}^{-}\right)$dan kemudian menjadi nitrat $\left(\mathrm{NO}_{3}{ }^{-}\right)$, bentuk inilah yang dapat diserap oleh tanaman. Nitrat yang tersisa dalam tanah mengalami denitrifikasi ialah suatu reaksi reduksi $\mathrm{NO}_{3}{ }^{-}$dan atau $\mathrm{NO}_{2}{ }^{-}$ menjadi gas $\mathrm{NO}, \mathrm{N}_{2} \mathrm{O}$ dan atau $\mathrm{N}_{2}$ yang dikatalisis oleh jasad renik pedenitrifikasi (Firestone, 1982 ; Zech et al., 1997 ; Regina, 1996).

Proses denitrifikasi merupakan salah satu jalur hilangnya nitrat dari larutan tanah dan terjadi hanya dalam keadaan lingkungan anaerob (Luo et al., 1999 ; Otabbong, et al., 1993; Regina, 1996; Rückauf et al., 2004). Kehilangan N pada sistem usahatani jagung manis di lahan gambut dapat dikurangi dengan menggunkanan pupuk yang lambat terurai seperti pupuk organik dan diberikan secara bertahap atau beberapa kali sesuai dengan fase pertumbuhan dan perkembangan tanaman. Menurut Torstensson, et al., (2006), bahwa kegiatan secara organik selain lebih ramah lingkungan, juga efisien dalam pengelolaan hara nitrogen dan dapat mengurangi kehilangan nitrogen karena pencucian (leaching) dan penguapan (volatilisasi). 


\section{KESIMPULAN}

Kehilangan nitrogen melaui pencucian (leaching) sebesar $5.62 \mathrm{~kg} \mathrm{~N}^{-1}$ atau 7.15 $\%$. Kehilangan lainnya yang diprediksi penguapan (volatilisasi) sebesar $9.78 \mathrm{~kg} \mathrm{~N}^{-}$ ${ }^{1}$ atau $12.45 \%$. Total kehilangan nitrogen sebesar $19.60 \%$, sehingga sistem usahatani jagung manis di lahan gambut Kelurahan Kalampangan Kota Palangka Raya dapat dikatagorikan tidak efisien.

\section{DAFTAR PUSTAKA}

Ahmad-Shah, A., M. Radzi-Abbas, dan A.S. Mohd-Jamil. 1992. Characteristics of tropical peat under a secondary forest and an oil palm plantation in Selangor, Malaysia. Proocedings of the 9th International Peat Congress. Uppsala, Sweden. (1) : 256-269.

Alvarez, R, Steinbach, H. S, Grigera, S. M., Cartier G., Obregon, S. T and R. Gracia. 2004. The Balance Sheet Method as a Conceptual Framework for Nitrogen Fertilization of Wheat in a Pampain Agroecosystem. Agronomy Journal. (96) : 1050 1057.

Barton, L, Schipper, L A., Barkle, G F and McLeod, M. 2005. Land Application of Domestic Effluent onto Four Soil Types: Plant Uptake and Nutrient Leaching. Journal of Environmental (34) : $635-643$.

Firestone, M.K. 1982. Biological denitrification.Nitrogen In Agricultural Soils. Agronomy (22) : 289-326.

Grimshaw, H. J. and Dolske, D.A. 2002. Rainfall consentrations and wet atmospheric deposition of phosphorus and other constituens in Florida. USA. Water, Air and Soil Pollution. (137) : $117-140$
Kaye, J.P., dan S.C. Hart. 1997. Competition for nitrogen between plants and soil microorganisms. Trend in Ecology and Evolution (12): 139-143.

Hayashi, K., Matsumoto, N., Hayashi, E. T., Abdoulaye, T., Shinjo, H., Tabo, R., Matsunaga, R., and Tobita, S. 2012. Estimation of nitrogen flow within a village-farm model in Fakara region in Niger, Sahelian zone of West Africa. Nutrient Cycling in Agrosystems (92) : 289 - 304. Kluwern Academik Publisher. Netherlands.

Hayden, M J and Ross, Donald S. 2005. Denitrification as a Nitrogen Removal Mechanism in a Vermont Peatland. Journal of Environmental Quality (340) : 2052- 2061

Hayes, R.J. 1986. Origin, distribution and cycling of nitrogen in terrestrial ecosystems.Dalam: R.J. Hayes (ed.), Mineral Nitrogen In The Plant-Soil System. Academic Press, London. pp : $1-51$.

Hepperly, P., L. Don, U. C. Ziegler, S. Rita, R. Carolyn. 2009. Compost, Manure and Synthetic Fertilizer Influences Crop Yields, Soil Properties Nitrat Leaching and Crop Nutrieient Content. Compost Science \& Utilization (17) : 117 - 126.

Hoffman, M and H. Johnson. 1999. A method for assessing generalished nitrogen leaching estimatis for agriculture land. Enviromantal modeling and assessment (4) : $35-44$

Jansson, S.L. and J. Persson. 1982. Mineralization and immobilization of soil nitrogen. Nitrogen In Agricultural Soils. Agronomy (22) : 229-252.

Knudsen, M.T., I.S. Kristensen, J. Benrtsen.B.J. Petersen and E.S Kristensen. 2006. Estimated $N$ leaching losses for organic and conventional farming in Denmark. Journal of Agricultural Science (144) : 135-149. 
Luo, J., R.W. Tillman, and P.R. Ball. 1999. Factors regulating denitrification in a soil under pasture. Soil Biology \& Biochemistry (31) : 913-927.

Moore, T. R., J. A. Trofymow, M. Siltanen and L. M. Kozak. 2008. Litter decomposition and nitrogen and phosphorus dynamics in peatlands and uplands over 12 years in central Canada. Oecologia (157) : 317-325.

Otabbong, E., \& B. Lindén. 1993. Nitrogen transformations and nitrate control in cultivated organic soils: A review. International Peat Journal (5) : 75-94.

Radjagukguk, B. 1997. Peat soil of Indonesia: Location, classification, and problems for sustainability.pp. 45-54. In J.O. Rieley and S.E. Page $(E d s$.$) .Biodiversity and Sustainability$ of Tropical Peat and Peatland. Proceedings of the International Symposium on Biodiversity, Environmental Importance and Sustainability of Tropical Peat and Peatlands, Palangkaraya, Central Kalimantan 4-8 September 1999. Samara Publishing Ltd. Cardigan. UK.

Raubuch, M., F. Beese, T. Bolger, J.M. Anderson, M.P. Berg, M.M.Couteaux, P. Ineson, F. McCarthy, P. Splatt, H.A. Verhoef, and T. Willison. 1998. Acidifying processes and acid-base reactions in forest soils reciprocally transplanted along a European transect with increasing pollution. Biogeochemistry (41) : 71-88

Regina, K., H. Nykänen, J. Silvola, and P.J. Martikainen. 1996. Fluxes of nitrous oxide from boreal peatlands as affected by peatland type, water table level and nitrification capacity. Biogeochemistry (35) : 401-418
Rückauf, U., J. Augustin, R. Russow, and W. Merbach. 2004. Nitrate removal from drained and reflooded fen soils affected by soil $N$ transformation processes and plant uptake. Soil Biology \& Biochemistry (36) : 77-90.

Salmeron, F, Miranda, Bath, B., Eckersten, H., Forkman, J., and Wivstad, M. 2007. Aboveground nitrogen in relation to estimated total plant uptake in maize and bean. Nutrient Cycling in Agrosystems (79) : 125139. Kluwern Academik Publisher. Netherlands.

Sun, B., Chen, D., Li, Y., and Wang, X. 2008. Nitrogen leaching in an upland cropping system on an acid soil in subtropical China: lysimeter measurements and simulation. Nutrient Cycling in Agrosystems (81) : 291- 303. Kluwern Academik Publisher. Netherlands.

Torstensson, G, H. A. Helena and L. Bergstrom. 2006. Nutrient Use Efficiencies and Leaching of Organic and Conventional Cropping Systems in Sweden. Agronomy Journal; May/Jun 2006; (98); 603-615

Zech, W., N. Senesi, G. Guggenberger, K. Kaiser, J. Lehmann, T.M. Miano, A. Miltner, and G. Schroth. 1997. Factors controlling humification and mineralization of soil organic matter in the tropics. Geoderma (79) : 117161.

Zhao, C., C. Hu, W. Huang, X. Sun, Q. Tan and H. Di. 2010. A lysimeter study of nitrate leaching and optimum nitrogen application rates for intensively irrigated vegetable production systems in Central China. J Soils Sediments (10) : 9-17 